\title{
Experimental study on the solidification and influence factors of MSW stabilized soil
}

\author{
Zhiping Wang ${ }^{1, a}$, Chenglin Lan ${ }^{1}$ \\ ${ }^{1}$ Department of Civil Engineering, Zhejiang College of Construction, Hangzhou 311231, China
}

\begin{abstract}
The effect of kinds and dosage of curing agent on the curing effect and strength characteristics of municipal solid waste (MSW) stabilized soil is very obvious. In order to reveal these effects, this paper uses cement, fly ash, lime and gypsum as main curing agent and additives to make MSW stabilized soil samples of different components and contents and its strength is obtained using unconfined compressive strength test. The results showed that the curing age, dosage of cement, fly ash, lime and gypsum have effect on the strengths of stabilized MSW soil. The bigger the content of cement and fly ash, the higher the strength of stabilized soil. But the amount of lime and gypsum has a critical value. Within the critical value, the strength of the stabilized soil increases with the increasing of the content of the additives, and decreases with the increase of the additives content if the content of the additives exceeds the critical value. The curing age has much effect on the strength of the stabilized soil. The strength of the samples for 7 days is far less than that for 28 days. This can be explained that: when the curing agent is added into the stabilized soil, the connection among the particles of the MSW soil is changed from weak connection to bond connection, and therefore the strength of the curing MSW soil is improved.
\end{abstract}

\section{Introduction}

With the rapid economic growth, people's living standard is improved and the progress of human civilization is promoted. But at the same time, there also causes many new problems, such as expansion of population, traffic congestion, environmental degradation, housing, employment difficulties, etc., of which the most prominent one is the sharp increase of the city waste production. These wastes not only pollute the environment, destruct city landscape, but also spread the disease, threaten human health and life safety. At present, the main municipal solid waste disposal methods include composting, incineration, landfill and comprehensive treatment method, of which the landfill is considered most economic and feasible method of city solid waste. The sanitation department collects the municipal garbage and transports it to the landfill site, spreads it in each layer with thickness of $2.5-3 \mathrm{~m}$ in the landfill area. The garbage layer is compacted using the mechanical machine. Finally, the clay layer with thickness of $15 \sim 30 \mathrm{~cm}$ is put on the upper part of the waste soil and compacted again and a daily landfill soil unit is therefore formed. A complete sanitary landfill is composed of several to dozens of the daily landfill layers. In the process of urban development, many buildings will be built in the original landfill and urban roads may also run through landfill for the reason of city size expanding. In order to meet the needs of the development of the city, the waste land base

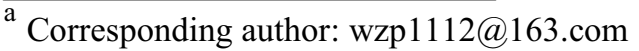

needs certain treatment, so as to further develop and reuse of it.

Because the MSW soil itself has high organic content, high porosity, complex composition and poor cohesion between garbage particles, the key to solve the problems are the foundation strength and uneven settlement when use the land resources of landfill, i.e., the reinforcement of MSW soil. At present, the research mainly focuses on the landfill settlement calculation ${ }^{[1-6]}$, and research on the reinforcement of the MSW soil is less ${ }^{[7-8]}$. For example, Zhao ${ }^{[1]}$ studied both the physical index and the engineering characteristics of stale waste using physicomechanical tests for many groups of stale waste from one landfill in Chongqing, China, and obtained some basic physical indexes of the waste, such as the composition, water content, density and pore ratio. From the analysis of the triaxial stress-strain curves, a division of the curve into four stages is put forward. The influences of cement content, density, water content and age on the deformation behavior in the four stages are given. Shi ${ }^{[7]}$ made investigation on the unconfined compressions of artificial municipal solid waste in under-degradation or in-degradation or past-degradation, mixed with cement $25 \%, 35 \%$ and $45 \%$ at different maintenance periods. The hardening stress strain curves and the strength law of artificial municipal solid waste mixed with cement versus maintenance period and cement content as well as degradation phase is obtained. $\mathrm{Liu}^{[8]}$ used fly ash and cement mixture as stabilizer to study the strength of MSW with relationship of different amount of stabilizer 
and different curing period by means of unconfined strength test. The factors and variation of the MSW strength is analyzed. The price of cement, fly ash, lime and gypsum is very low. When these substances are used as curing agent and are mixed into the MSW soil, the hydrolysis reaction, hydration reaction and ion exchange will happen among the MSW soil and the curing agents, where the MSW stabilized soil is formed, and finally the strength of the MSW soil is improved greatly. The MSW stabilized soil is a mixture of various curing materials, and there has many factors affecting its strength. Therefore, it is necessary to carry out further research on the influence factors and strength mechanism of MSW stabilized soil. In order to further reveal the strengthdeformation characteristics and its influence factors of the MSW stabilized soil, this paper uses laboratory tests and studies the strength mechanism and characteristics, and analyzes the effect of curing age, the content of curing agents and additives on the strength of MSW stabilized soil, and analyzes the influence factors and change law of the strength of the MSW stabilized soil. The microstructure and pore characteristics of the MSW stabilized soil mixed with different content and kinds of curing agent is explained in great detail. The research results and curing agent can be used as conference when stabilizing municipal solid waste soil and treatment of discarded clay or MSW soil.

\section{MSW soil and Curing materials}

\subsection{MSW soil}

The component of the MSW soil is very complex. Its engineering characteristics are affected by many factors. According to the domestic and foreign research and analysis, its components can be broadly divided into plastics, rubber, textile fibre, paper, kitchen waste, bone, wood, ash, glass, metal and other kinds of organic matter. The municipal solid waste (MSW) can also be divided into one-dimensional content with its length and sample volume ratio: wooden or mental strips, two-dimensional composition content with the total area of the sample volume ratio: plastic film, glass, and three-dimensional content with the volume percentage measured: glass bottles, according to the different shapes and sizes.

The MSW soil used in the experiment can be obtained from landfill drill, but the different filling time and uneven specimen will make the test results very discrete, which is difficult to analyze the related factors. Therefore, the waste soil used in the experiment is selfmade by artificial decomposition, and it was prepared by different degradation time of MSW curing soil sample, so as to eliminate some accidental factors. Based on the statistical analysis of the sorting data of domestic waste landfill sites and the composition of the waste soil in the strength test of MSW in the author's previous experiment, the composition of the waste soil used are: $2.0 \%-8.0 \%$ kitchen waste, $0.0 \%-5.0 \%$ waste paper, $4.0 \%-10.0 \%$ fiber, $1.0 \%-3.0 \%$ bamboo- wood products, $8.0 \%-18.0 \%$ rubber and plastic, $3.0 \%-5.0 \%$ ceramics and $63.0 \%-68.0 \%$ silt, where kitchen waste is replaced with wheat bran, fiber replaced with cloth, bamboo- wood products replaced with sawdust, while ceramics replaced with glass. All the MSW soil constituents are referred to mass percentage after drying. With the passage of time, the organic matter in the MSW soil will degrade and its contents will change. Different components of MSW soil represent different MSW landfill time. The kitchen waste and organic matter in the fresh MSW soil was the highest. The content of MSW soil used in the experiment is shown in Table 1. Part of the raw material used in the experiment is shown in Figure 1.

Table 1. The content of MSW soil.

\begin{tabular}{|c|c|c|c|c|c|c|c|}
\hline No. & \multicolumn{7}{|c|}{ Content $/ \%$} \\
\hline & wheat bran & waste paper & cloth & sawdust & rubber & glass & silt \\
\hline I & 8.0 & 5.0 & 5.0 & 3.0 & 8.0 & 4.0 & 68.0 \\
\hline II & 5.0 & 5.0 & 4.0 & 1.0 & 15.0 & 5.0 & 63.0 \\
\hline III & 2.0 & 0.0 & 10.0 & 1.0 & 18.0 & 3.0 & 64.0 \\
\hline
\end{tabular}

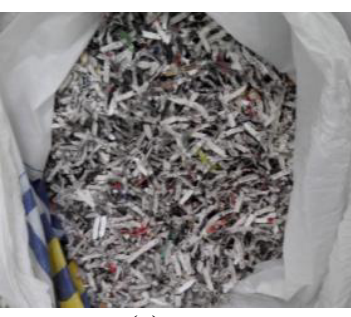

(a) waste paper

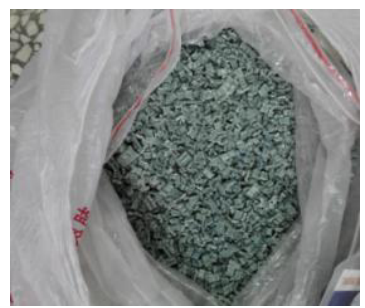

(c) rubber

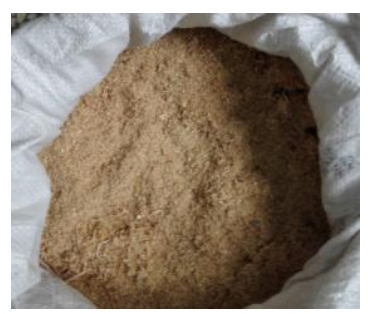

(b) sawdust

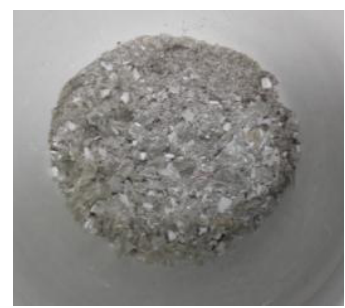

(d) glass
Figure 1. Part of the raw materials used in the MSW soil.

\subsection{Curing materials}

The main curing materials and additives used in the test are cement, fly ash, lime and gypsum. In order to study the strength characteristics of MSW stabilized soil, three kinds of MSW soil with different component is chosen, while the content of curing agent and additives are chosen as: cement: $15.0 \%, 20.0 \%, 25.0 \%$ and $30.0 \%$, lime: 0.0 and $3.0 \%$, gypsum: $0.0 \%, 3.0 \%$ and $5.0 \%$, and fly ash: $0.0 \%, 3.0 \%, 5.0 \%$ and $10.0 \%$, respectively. The cement is chosen from the $42.5 \#$ ordinary portland cement produced by Qianchao Cement Plant, Hangzhou. The gypsum is produced by Shanghai Baoping Building Materials Co. Ltd. The lime is produced by Yongfu County of Guangxi Jin Yingtai Co. Ltd. The fly ash is produced by Jiaxing Power Plant, Zhejiang province. The content of curing agent and additives are shown in Table 2 . 
Table 2. The content of curing agent and additives.

\begin{tabular}{|c|c|c|c|c|}
\hline kind & \multicolumn{4}{|c|}{ content $/ \%$} \\
\hline cement & 15.0 & 20.0 & 25.0 & 30.0 \\
\hline fly ash & 3.0 & 3.0 & 5.0 & 10.0 \\
\hline lime & 0.0 & 3.0 & & \\
\hline gypsum & 0.0 & 3.0 & 5.0 & \\
\hline
\end{tabular}

\section{Experimental results}

In order to reveal the kinds and dosage of curing agent and additives on the strength characteristics of stabilized MSW soil, the MSW soil samples prepared indoor were added into a certain dose of cement and cement- fly ash individually and solidified. The strength-strain curves are obtained using unconfined compressive strength test. The results are shown in Figure 2-4.

Figure 2 is the damage mode of the MSW stabilized soil sample. Usually, there are three kinds of soil damage mode: shear failure, drum damage and compaction form without significant damage surface. From Figure 2, it can be seen that the damage mode of the stabilized soil sample is shear failure. The damage mode is strictly connected with the confining pressure, curing period and curing content. If the confining pressure or the curing content is high, the damage mode of the stabilized soil may be changed to the compaction form.

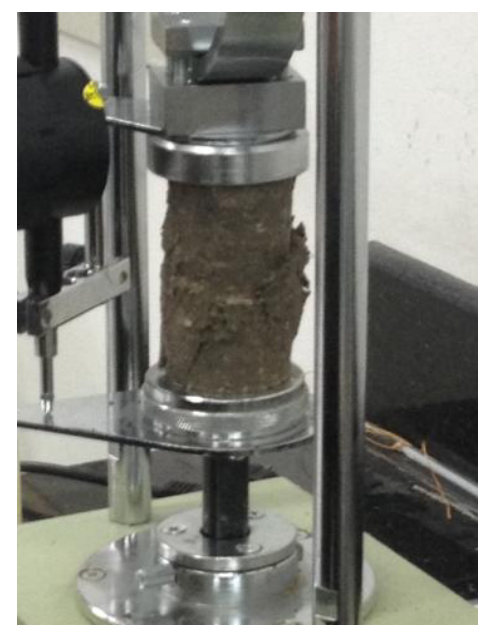

Figure 2. Damage mode of the stabilized soil sample

Figure 3 is the strength-strain relationship for MSW stabilized soil only using cement as curing agent. From the figure, it can be seen that: with the increasing of strain, the strength of the stabilized soil increases gradually. After passing the peak value, the strength of the soil decreases with the increasing of the strain. The mode of the stabilized soil shows the strain softening. The maximum of the strength is about $244.4 \mathrm{kPa}$.

This can be explained that: the chemical reactions happened when cement is added into the stabilized MSW soil, which includes: cement hydration reaction and ion exchange processes, volcanic ash reaction and carbonated, etc. Cement hydration reaction refers to the $\mathrm{C}-\mathrm{S}-\mathrm{H}$ gel generated during hydration, and has a high effect on the solidification, which can constitute a network structure. With the increase of cement content, the hydration products increase, and the pore of soil particles is filled, so that the bonding between soil particles is enhanced. The ion exchange is the equivalent exchange of $\mathrm{Ca}^{2+}$ of $\mathrm{Ca}(\mathrm{OH})_{2}$, with those of $\mathrm{Na}^{+}$or $\mathrm{K}^{+}$on the soil surface, so that the small particles become bigger particles, so as to improve the strength of stabilized soil. The volcanic ash reaction is that: when the number of $\mathrm{Ca}^{2+}$ formed in the process of cement hydration reaction is more than the amount of ion exchange, the excess number of $\mathrm{Ca}^{2+}$ will react with the $\mathrm{Al}_{2} \mathrm{O}_{3}, \mathrm{SiO}_{2}$ in the soil under alkaline conditions, to generate insoluble in water and stable compounds. Carbonation is the reaction of the cement hydration products $\mathrm{Ca}(\mathrm{OH})_{2}$ and water, $\mathrm{CO}_{2}$ to produce new products: $\mathrm{CaCO}_{3}$, and the strength of solidified MSW soil is therefore strengthened.

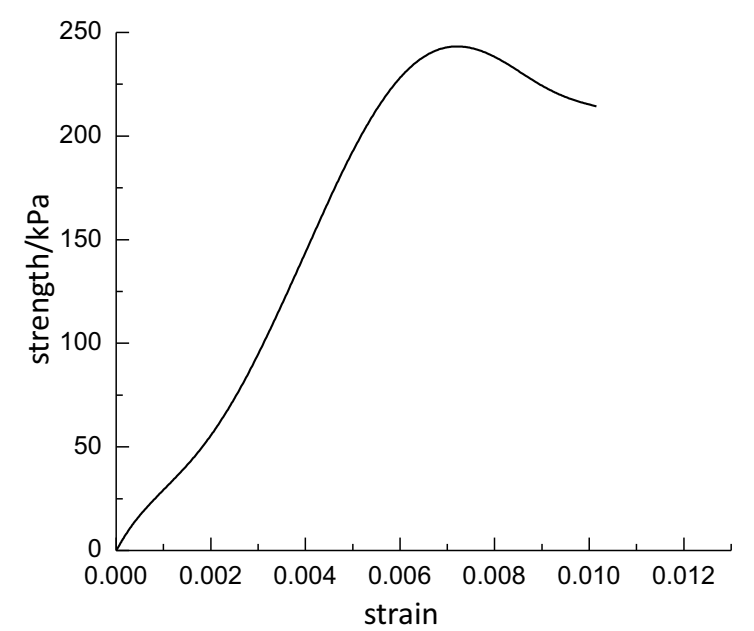

Figure 3. Strength-strain relationship for MSW soil solidified only using cement

Figure 4 is the relationship between the unconfined compressive strength and strain of MSW stabilized soil cured by $25 \%$ content of cement and $5 \%$ content of fly ash. From the figure, it can be seen that the change trend of the curve is similar with that of Figure 3. With the increase of the strain, the confined compressive strength of the stabilized soil increases gradually. After the strength reaches the peak value, it gradually decreases with the increase of the strain. The mode of the stabilized soil is still the strain softening. The maximum of the strength is about $1569.5 \mathrm{kPa}$, which is more than 6 times compared with Figure 3. It indicates that the strength of the waste stabilized soil can be greatly improved if mixed with cement and fly ash at the same time, which can improve several times than that mixed with cement only. This shows that the curing effect is better if fly ash is also introduced in the mixture at the same time when stabilizing the MSW waste soil.

The influence of fly ash on the early strength of solidified MSW soil is not obvious, and it mainly affects its later strength. This is due to the active $\mathrm{SiO}_{2}$ and $\mathrm{Al}_{2} \mathrm{O}_{3}$ in the fly ash with the cement hydration product $\mathrm{Ca}(\mathrm{OH}) 2$ produce volcanic ash reaction to form hydrated calcium silicate and hydration calcium aluminates, which are very stiffer, so that the soil gel. The volcanic reaction makes the content of $\mathrm{Ca}(\mathrm{OH})_{2}$ decreases continuously. In order to maintain the balance of chemical reactions, cement 
will continue to hydration. On the other hand, the fly ash also plays a role of filling small pores of stabilized soil because of its fine particles. Finally, the strength of stabilized soil is improved.

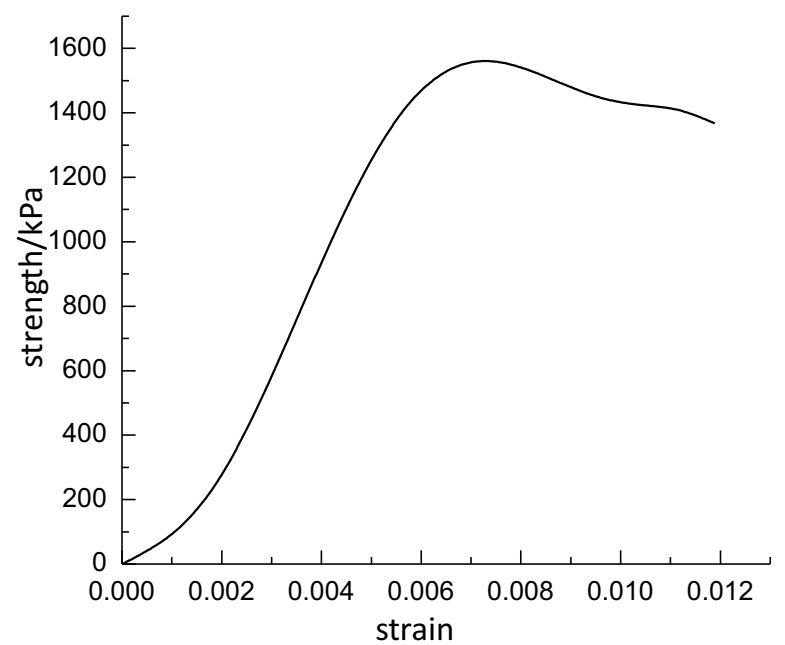

Figure 4. Strength-strain relationship for MSW soil solidified using cement and fly ash

\section{Summary}

Through the unconfined compressive strength test and single dosage test, the effect of kinds and dosage of curing agent (cement, fly ash, lime and gypsum, etc.) on the strength characteristics of MSW stabilized soil is revealed. The conclusions can be obtained from the analysis as follows:

(1) The MSW soil is made using wheat bran, waste paper, cloth, sawdust, rubber, plastic, glass and silt as raw materials.

(2) The results of the strength characteristics of the stabilized soil under different kinds and content of curing agent are obtained. From the test results, it can be obtained that the adding of appropriate content of additives can greatly improve the strength of stabilized soil.

(3) The strength of the MSW stabilized soil increases with the increase of cement content. This is due to that the chemical reactions of cement hydration reaction and ion exchange processes, volcanic ash reaction and carbonated, etc., happened when cement is added into the stabilized MSW soil. With the increase of cement content, the hydration products increase, and the pore of soil particles is filled, so that the bonding between soil particles is enhanced. Therefore, the strength of stabilized soil is improved.

(4) If the fly ash is mixed into the MSW soil, it can also increase the strength of the stabilized soil. But the influence of fly ash on the early strength of solidified MSW soil is not obvious, and it mainly affects its later strength. This is due to the active fly ash can also produce volcanic ash reaction to make the content of $\mathrm{Ca}(\mathrm{OH})_{2}$ decreases continuously. On the other hand, the fly ash also plays a role of filling small pores of stabilized soil because of its fine particles. Finally, the strength of stabilized soil is improved.

\section{Acknowledgement}

This work was financially supported by the Department of Housing and Urban-Rual Development of Zhejiang Province (2013Z009) and Department of education of Zhejiang Province (Y201432514). The supports are gratefully acknowledged.

\section{References}

1. Zhao Y, Li X, Lu Y, etc. Journal of Chongqing Jianzhu University. 30, 3 (2008)

2. Gao W, Tu F, Xiao Z, etc. Chinese Journal of Environmental Engineering. 4, 5 (2010)

3. Zhang W, Chen Y, Qiu Z. Rock and Soil Mechanics. 30, 11 (2009)

4. Zhao Y, Xie Q, Zhang Y, etc. Chinese Journal of Geotechnical Engineering. 36, 10 (2014)

5. Saeed KA, Kassim KA, Nur H, etc. KSCE Journal of Civil Engineering 19, 4 (2015)

6. Al-Amoudi OSB, Khan K, Al-Kahtani NS. Construction and Building Materials. 24, 10 (2010)

7. Shi J, Mao J. Rock and Soil Mechanics. 30, 7 (2009)

8. Liu L, Pang N, Wu P. Journal of Inner Mongolia University of Technology. 31, 3 (2012)

9. Li M, Zhu W, Ma D, Ji F. Chinese Journal of Geotechnical Engineering. 28, 4 (2006)

10. Horiuchi S, Uchiyama N, Odawara T,K Yasuhara. Journal of Geotechnical and Geoenvironmental Engineering, ASCE. 8, 3 (1996)

11. Fan $\mathrm{H}, \mathrm{Wu} \mathrm{P}, \mathrm{Gao} \mathrm{J}$, etc. Journal of Building Materials. 13, 5 (2010)

12. Huang Y, Zhou Z, Bai J, etc. Journal of Geotechnical Engineering. 32, 8 (2010) 